\title{
СОЦИАЛИЗАЦИЯ ЛИЧНОСТИ НЕСОВЕРШЕННОЛЕТНЕГО КАК САМОСТОЯТЕЛЬНЫЙ ПРЕДМЕТ КРИМИНОЛОГИЧЕСКОГО ИССЛЕДОВАНИЯ
}

\author{
Демидова-Петрова Е.В.
}

Аннотация. Осуществление научной диагностики причин преступности в целях ее сокращения и минимизации негативных последствий. Описывается процесс формирования личности в определенных сочиальных условиях, социальных группах, а также приобретения жизненного опыта, усвоения ценностей, норм, правил поведения. Рассматривается социальная среда личности. Проводится детальное рассмотрение понятия социальной среды. Приводятся основные стадии социализаџии личности, а так же ее виды. Автором предложены собственные определения социальной среды личности, а также социализации личности несовершеннолетнего. Исторический метод используется для анализа подходов к изучению причин преступности и способов противодействия ее проявлениям. Метод классификации использован для рассмотрения различных видов социализации В современных условиях поставлена точка в многовековом споре ученых о преобладании биологических или сочиальных причин преступности. Личность - биосоциальна. В связи с процессом усвоения социальных ролей выделяют различные виды сочиализачии: 1) поло-ролевая; 2) семейно-бытовая; 3) профессионально-трудовая; 4) субкультурно-групповая сочиализаџия.Под сочиализачией личности несовершеннолетнего в объективном смысле следует понимать этапы формирования личности индивида, его взаимодействие с окружающей микро и макро средой, на определенной территории, а также за определенный период времени, в субъективном смысле соииализация личности несовершеннолетнего представляет собой восприятие и отношение личности к окружающей его действительности и к системе факторов влияющих на его формирование.

Ключевые слова: сочиальная среда, несовершеннолетний, семья, личность, социализация, теория социализации, молодежные группировки, возраст, социальное развитие, общество.

С древнейших времен человечество осуществляет поиск путей «обуздания» преступности. Идеи полного искоренения преступности не оправдали себя, оказались утопическими, так как ее корни находятся в общественных противоречиях, которые вечны, и, следовательно, преступность тоже будут существовать всегда, пока существует человеческое общество. На современном этапе задача заключается в осуществлении научной диагностики причин преступности в целях ее сокращения, минимизации послед- ствий, а устанавливать причины заболеваний и устранять их необходимо 1 .

На протяжении многовековой истории становления криминологической науки менялись теории причин преступности. Вместе с тем их сущность всегда справедливо концентрировалась вокруг про-

\footnotetext{
${ }^{1}$ Ювенальная криминология: учебник для студентов, обучающихся по специальности «Юриспруденция» / В. А. Лелеков, Е. В. Кошелева.—-2-е изд., перераб. и доп.M., 2014.- C. 73.
} 
блем личности и социальной микро- и макросреды. Неоднозначно оценивались так называемые биологические и социальные факторы. В современных условиях поставлена точка в многовековом споре ученых о преобладании биологических или социальных причин. Личность - биосоциальна. Преступление - результат взаимодействия личности и социальной микро- и макросреды.

В данном контексте, представляется необходимым более детальное рассмотрение понятия социальной среды.

Социальная среда - это совокупность материальных, экономических, социальных, политических и духовных условий соществования, формирования и деятельности индивидов и социальных групп.

Если рассматривать социальную среду как среду, свойства и характеристики которой постоянно изменяются, то в литературе используется понятие социальный континуум ${ }^{1}$.

С точки зрения философии социальная среда - это окружающие человека общественные, материальные и духовные условия его существования, формирования и деятельности.

Социальная среда в широком смысле (макросреда) охватывает общественно-экономическую систему в целом - производственные силы, совокупность общественных отношений и институтов, общественного сознания, культуру данного общества; социальная среда в узком смысле (микросреда), будучи элементом социальной среды в целом, включает непосредственно социальное окружение человека - семью, трудовой, учебный и иной коллективы и группы. Социальная среда оказывает решающее воздействие на формирование и развитие личности. В то же время под влиянием творческой активности, деятельности человека она изменяется, преобразуется, и в процессе этих преобразований изменяются и сами люди ${ }^{2}$.

В педагогике социальная среда понимается, как окружающий человека социальный мир, включающий в себя условия становления, существования, развития и деятельности людей, неразрывно связанные с субъект-субъектными и с объект-субъектными отношениями, в которые эти люди вовлечены ${ }^{3}$.

\footnotetext{
${ }^{1}$ http:// ru.wikipedia.org

${ }^{2}$ См.: Философский энциклопедический словарь / Гл. ред. Л. Ф. Ильичев, П.Н. Федосеев, С. М. Ковалев, В.Г. Панов.M., 1983.

${ }^{3}$ См.: Педагогическая энциклопедия: Воспитание здорового образа жизни учащихся.- M., 2005.
}

По мнению Л. С. Выготского социальная среда содержит в себе бесчисленное множество самых различных сторон и элементов. Элементы всегда находятся в жесточайшем противоречии и борьбе друг с другом, и вся среда должна пониматься не как статическая, первоначальная и устойчивая система элементов, но как диалектически развивающийся динамический процесс. Революционер может оказаться с социальной точки зрения более приспособленным к высшим тенденциям среды, чем карьерист, потому что он приспособлен к социальной динамике, а не к социальной статике.

Отношение человека к среде всегда должно носить характер активности, а не простой зависимости. Поэтому приспособленность к среде может означать жесточайшую борьбу с отдельными элементами среды и всегда известные активные взаимоотношения с ней. Следовательно, в одной и той же социальной среде возможны совершенно разные социальные установки индивида, и все дело в том, в каком направлении будет воспитана эта активность ${ }^{4}$.

Интересной позиции придерживается С. М. Вишняков, понимая под социальной средой окружающие человека общественные, материальные и духовные условия его существования и деятельности. Среда в широком смысле (макросреда) охватывает общественно-экономическую систему в целом - производительные силы, общественные отношения и институты, общественное сознание и культуру. Среда в узком смысле (микросреда) включает непосредственное окружение человека - семью, трудовой, учебный и др. коллективы и группы. Среда оказывает решающее воздействие на формирование и развитие личности; в то же время под влиянием деятельности человека она изменяется, и в процессе этих преобразований изменяются сами люди Мы придерживаемся данной точки зрения, полагая, что именно это определение социальной среды является наиболее полным и адекватно отражающим его сущность.

В свою очередь видится необходимым предложить собственное определение социальной среды личности. Под социальной средой личности следует понимать не только окружающую

\footnotetext{
${ }^{4}$ См.: Выготский Л. С. Авторский терминологический словарь.- М., 2014.

${ }_{5}^{5}$ См.: Вишняков С. М. Профессиональное образование. Словарь. Ключевые понятия, термины, актуальная лексика.-М., 1999.
} 
его микро- и макросреду, но и экономическую, политическую, духовную, морально-нравственную обстановку, а также традиции, исторически обусловленные на определенной территории и в определенный промежуток временни, Только в совокупности, все перечисленные выше факторы и оказывают доминирующее влияние, воздействие на основные этапы формирования, а именно, социализацию личности индивида.

Социализация, как известно, представляет собой процесс формирования личности в определенных социальных условиях, социальных группах, а также приобретения жизненного опыта, усвоения ценностей, норм, правил поведения.

Процесс формирования личности принято рассматривать как социализацию, т.е. процесс наделения личности общественными свойствами, выбора жизненных путей, установления социальных связей, формирования самосознания и системы социальной ориентации, вхождения в социальную среду, приспособления к ней, освоения определенных социальных ролей и функций ${ }^{1}$. Именно в этот период возникают и закрепляются реакции на возникающие жизненные ситуации, наиболее характерные для предпочтений данного человека.

Г. Тард основным механизмом социализации провозгласил подражание, регулируемое обществом через свои социальные институты - систему образования и воспитания, семью, общественное мнение, а отношения «учитель - ученик» - типовым социальным отношением ${ }^{2}$.

Г. М. Андреева определяет социализацию следующим образом: «Социализация — это двусторонний процесс, включающий в себя, с одной стороны, усвоение индивидом социального опыта путем вхождения в социальную среду, систему социальных связей; с другой стороны, процесс активного воспроизводства индивидом системы социальных связей за счет его активной деятельности, активного включения в социальную среду... человек не просто усваивает социальный опыт, но и преобразовывает его в собственные ценности, установки, ориентации» ${ }^{3}$.

А. В. Мудрик, автор наиболее основательной теории социализации в отечественной литера-

\footnotetext{
${ }_{1}^{1}$ Антонян Ю. М., Эминов В. Е. Личность преступника. Криминолого-психологическое исследование: монография.- М., 2014.- С. 34.

${ }^{2}$ См.: Тард Г. Социальная логика.- СПб., 1996.

${ }^{3}$ См.: Андреева Г.М. Социальная психология: учебник.M., 2001.
}

туре, дает следующее определение: социализация - это «развитие и самоизменение человека в процессе усвоения и воспроизводства культуры, что происходит во взаимодействии человека со стихийными, относительно направляемыми и целенаправленно создаваемыми условиями жизни на всех возрастных этапах». Сущность социализации состоит в сочетании приспособления и обособления человека в условиях конкретного общества. Также А. В. Мудрик отмечал, что в науку о человеке термин «социализация» пришел из политэкономии, где его первоначальным значением было «обобществление» - земли, средств производства ${ }^{4}$. Применительно к человеку он нашел отражение в связи с развитием социологии.

В работе американского социолога Ф.Г. Гиддингса «Теория социализации» (1887 г.) термин «социализация» применяется в значении, близком к современному, - развитие социальной природы или характера индивида, подготовка человеческого материала к социальной жизни ${ }^{5}$.

Социализация личности в самом общем представлении есть процесс усвоения (интериоризации) ею принятых в обществе социальных норм и правил ${ }^{6}$.

По мнению Л. В. Мардахаева, социализация определяет динамику социального становления человека на разных этапах возраста с учетом его своеобразия, среды жизнедеятельности и самопроявления, а также социального воспитания. Основными комнонентыми социализации человека автор называет:

1) формирование и развитие сознания, мировоззрения человека (усвоение языка, взглядов, интересов, социальных ценностей, идеалов);

2) овладение культурой, присущей данному обществу, социальной общности, группе (правилами, нормами и шаблонами поведения);

3) усвоение социальных ролей, навыков общения, самопроявления в среде жизнедеятельности;

4) накопление опыта социального поведения ${ }^{7}$.

\footnotetext{
${ }^{4}$ См.: Мудрик А. В. Социальная педагогика. 6-ое изд., перераб и доп.- М., 2007.

${ }^{5}$ Мардахаев Л.В. Социальная педагогика. Основы курса: учебник. - 5-е изд., перераб. и доп.-М., 2011.-С. 60.

${ }^{6}$ Побегайло А.Э. Семейное неблагополучие в системе детерминации преступного поведения несовершеннолетних: дис. ... канд. юрид. наук.- М., 2006. - С. 16.

${ }^{7}$ Мардахаев Л. В. Социальная педагогика. Основы курса: учебник.— 5-е изд., перераб. и доп.-М., 2011.—С. 61.
} 
Социализация рассматривается как процесс, усвоение, проявление и результат социального формирования личности.

Как процесс она означает социальное становление и развитие личности в зависимости от характера взаимодействия человека с социокультурной средой обитания, адаптации к ней и самореализации с учетом индивидуальных возможностей. В ее процессе человек формируется как часть того общества, к которому он принадлежит.

Как условие - это свидетельство наличия социума, который необходим человеку для естественного социального развития как личности.

Как проявление - это социальная реакция человека с учетом его возраста и социального развития в системе конкретных общественных отношений. Так судят об уровне социального развития, социализированности человека.

Как результат она является социально-педагогической характеристикой человека и его особенностей как социальной единицы общества в соответствии с возрастом. Ребенок в развитии может отставать или опережать сверстников. Социализация как результат характеризует степень его социального совершенства по отношению к сверстникам.

По своей сущности социализация определяет своеобразие социального развития, самореализации человека, усвоения и воспроизводства им культуры общества на протяжении всей жизни. Постепенно человек, формируясь как личность, расширяет и углубляет свои социальные, социокультурные интересы, идеалы, ценности, усваивает и совершенствует различные социальные роли, приобретает опыт социального поведения ${ }^{1}$. Также ряд авторов полагает, что социализация личности как активный процесс длится не всю жизнь, а лишь период, необходимый для восприятия комплекса норм, ролей, установок и т.д., т.е. на протяжении времени, нужного для становления индивида как личности.

Как правило, выделяются следующие стадии социализации:

1) первичная, или ранняя, социализация (от рождения до подросткового возраста);

2) стадия индивидуализации, характеризующаяся стремлением индивида выделить себя среди других, критически осмыслить общественные нормы поведения;

\footnotetext{
${ }^{1}$ Мардахаев Л.В. Социальная педагогика. Основы курса: учебник.-5-е изд., перераб. и доп.-М., 2011.—C. 62-63.
}

3) стадия интеграции, отражающая желание человека найти свое место в жизни, «влиться» в общество;

4) трудовая стадия;

5) послетрудовая стадия ${ }^{2}$.

Необходимо дополнить вторую стадию социализации этапом, характеризующимся стремлением родителей либо близких родственников ребенка выделить его, обособить от окружающих его детей, чем ярко демонстрируется его превосходство над другими. Данные действия, как правило, имеют крайне негативные влияния и влекут за собой неблагополучные последствия в воспитании и формировании личности ребенка.

Также в литературе выделяются агенты первичной и вторичной социализации:

- $\quad$ агенты первичной социализации - факторы непосредственного взаимодействия с человеком, оказывающие на его социализацию существенное влияние на ранних этапах жизни: родители, братья и сестры, бабушки и дедушки, близкие и дальние родственники, няни, друзья семьи, сверстники, учителя, тренеры, врачи, лидеры молодежных группировок;

- агенты вторичной социализации - факторы, опосредованно или формально окружающие человека и оказывающие на его социализацию существенное влияние на поздних этапах жизни: учреждения и институты, представители администрации школы, университета, предприятия, армии, правоохранительных органов, церкви, государства, телевидения, радио, печати, партии, суда ${ }^{3}$.

В связи с процессом усвоения социальных ролей выделяют различные виды социализации: поло-ролевая социализация представляет собой освоение человеком опыта социального поведения в соответствии с его половой принадлежностью и проявлением его в повседневной жизни в зависимости от возраста и измененяемых с ним социального положения и роли в обществе (мальчик, девочка, невеста или жених, муж или жена, отец или мать);

семейно-бытовая социализация, способствующая усвоению определенной семейной роли в соответствии с социальным положением в семье. Она проявляется в усвоении и проявлении

\footnotetext{
${ }^{2}$ См.: Баранов П. П., Курбатов В.И. Юридическая психология.- М., 2006.

${ }^{3}$ Мардахаев Л. В. Социальная педагогика. Основы курса: учебник.— 5-е изд., перераб. и доп.-М., 2011.—С. 63.
} 
опыта семейной жизни, укреплении семейных отношений, ведении хозяйства, воспитании детей; профессионально-трудовая социализация осуществляется на основе социального опыта выполнения человеком определенной профессиональной деятельности;

субкультурно-групповая социализация предполагает освоение социальных ролей с учетом той культуры среды, где человек жил, учился, общался, трудился. Каждый регион имеет социокультурное своеобразие поведения, общения, речи, что способствует формированию своеобразия социума. Субкультурно-групповая социализация отличает людей различных регионов, национальной и религиозной принадлежности, социального окружения, возраста, профессиональной деятельности ${ }^{1}$.

Особенно важную роль в формировании личности играет первичная социализация, когда ребенок еще бессознательно усваивает образцы и манеры поведения, типичные реакции старших на те или иные проблемы. Как показывают психологические исследования личности преступников, уже взрослым человек часто воспроизводит в своем поведении то, что запечатлелось в его психике в период детства.

Дефекты первичной, ранней социализации в родительской семье могут иметь криминогенное значение в первую очередь потому, что ребенок еще не усвоил других положительных воздействий, он полностью зависим от старших и совершенно беззащитен перед ними ${ }^{2}$. Поэтому вопросы формирования личности в семье заслуживают исключительного внимания.

Семья является важнейшим институтом социализации личности, каналом включения молодого поколения в культурную традицию. Именно в семье человек получает первый опыт социального взаимодействия. На протяжении какого-то времени семья вообще является для ребенка единственным местом получения такого опыта. Затем в жизнь человека включаются детский сад, школа, улица. Однако и в это время семья остается одним из важнейших, а иногда и наиболее важным, фактором социализации личности․․

\footnotetext{
${ }^{1}$ Мардахаев Л.В. Социальная педагогика. Основы курса: учебник. - 5-е изд., перераб. и доп.-М., 2011.—С. 63.

${ }^{2}$ Антонян Ю.М., Эминов В.Е. Личность преступника. Криминолого-психологическое исследование: монография.- М., 2014.— С. 34.

${ }^{3}$ Побегайло А.Э. Семейное неблагополучие в системе детерминации преступного поведения несовершеннолетних: дис. ... канд. юрид. наук.- М., 2006.- С. 16.
}

«Семью можно рассматривать в качестве модели и формы базового жизненного тренинга личности. Социализация в семье происходит как в результате целенаправленного процесса воспитания, так и по механизму социального научения. В свою очередь, сам процесс социального научения также идет по двум основным направлениям. С одной стороны, приобретение социального опыта идет в процессе непосредственного взаимодействия ребенка с родителями, братьями и сестрами, а с другой - социализация осуществляется за счет наблюдения особенностей социального взаимодействия других членов семьи между собой» ${ }^{4}$.

Обязательному учету в процессе социализации и формирования личности подростка подлежат так называемые кризисы возраста. Так, Л.С. Выготский выделял кризис новорождения, одного года, трех, семи и тринадцати лет. Кризисы новорождения, трех лет и подросткового возраста относят к так называемым большим кризисам. Они характеризуются коренной перестройкой отношений ребенка и общества. Малые кризисы (кризис одного года, семи лет, 17-18 лет) проходят относительно спокойно, связаны с приобретением человеком опыта, знаний и умений, развитием самостоятельности и самоопределения ${ }^{5}$. Кризисы возраста означают особый психологический этап, переход личности к новому, высшему периоду развития. Из всех переживаемых ребенком кризисных периодов наиболее сложным как для него самого, так и тех, кто занимается его воспитанием, а именно родителей, учителей, является кризис подросткового возраста.

Анализ причин и условий, способствующих возникновению дефектов социализации, выделяет наиболее общие признаки, которые используются для описания характеристики семьи: численность семьи, структура (число поколений); характер семейной власти и взаимоотношений между отдельными членами семьи и входящими в нее возрастными, половыми и другими «подгруппами»; социальные функции (воспроизводство поколений, социализация, организация и проведение досуга, взаимопомощь и сотрудничество, хозяйственно-потребительская функция и др. $)^{6}$.

\footnotetext{
${ }^{4}$ Реан А.А. Развитие и социализация личности в семье.HRL.: http://narcom.ru/parents/parents/20.html

${ }^{5}$ См.: Выготский Л.С. Психология.- М., 2002.

6 Зарипова Д. М. Борьба с преступностью маргинальных групп населения: теоретические и прикладные проблемы.-Казань, 2000.-С. 53, 54.
} 
Итак, социализацию личности несовершеннолетнего можно понимать в объективном и субъективном аспектах.

Под социализацией личности несовершеннолетнего в объективном смысле следует понимать этапы формирования личности индивида, его взаимодействие с окружающей микро и макро средой, на определенной территории, а также за определенный период времени, в субъективном смысле социализация личности несовершеннолетнего представляет собой восприятие и отношение личности к окружающей его действительности и к системе факторов влияющих на его формирование.

\section{Библиография}

1. Андреева Г. М. Социальная психология: учебник.- М., 2001.

2. Антонян Ю. М., Эминов В.Е. Личность преступника. Криминолого-психологическое исследование: монография.- М., 2014.

3. Баранов П.П., Курбатов В. И. Юридическая психология.- М., 2006.

4. Вишняков С. М. Профессиональное образование. Словарь. Ключевые понятия, термины, актуальная лексика.- М., 1999.

5. Выготский Л. С. Авторский терминологический словарь.-М., 2014.

6. Выготский Л. С. Психология.—- М., 2002.

7. Зарипова Д. М. Борьба с преступностью маргинальных групп населения: теоретические и прикладные проблемы. - Казань, 2000.

8. Мардахаев Л. В. Социальная педагогика. Основы курса: учебник. - 5-е изд., перераб. и доп.M., 2011.

9. Мудрик А. В. Социальная педагогика. 6-ое изд., перераб и доп.- М., 2007.

10. Педагогическая энциклопедия: Воспитание здорового образа жизни учащихся. - M., 2005.

11. Побегайло А.Э. Семейное неблагополучие в системе детерминации преступного поведения несовершеннолетних: дис. ... канд. юрид. наук.- М., 2006.

12. Реан А. А. Развитие и социализация личности в семье.— Режим доступа: http://narcom.ru/parents/ parents/20.html

13. Тард Г. Социальная логика.-СПб., 1996.

14. Философский энциклопедический словарь / Гл. ред. Л. Ф. Ильичев, П. Н. Федосеев, С. М. Ковалев, В. Г. Панов. - М., 1983.

15. Ювенальная криминология: учебник для студентов, обучающихся по специальности «Юриспруденция» / В. А. Лелеков, Е. В. Кошелева. — 2-е изд., перераб. и доп.— М., 2014.

\section{References (transliterated)}

1. Andreeva G. M. Sotsial'naya psikhologiya: uchebnik. - M., 2001.

2. Antonyan Yu.M., Eminov V.E. Lichnost» prestupnika. Kriminologo-psikhologicheskoe issledovanie: monografiya.-M., 2014.

3. Baranov P. P., Kurbatov V. I. Yuridicheskaya psikhologiya. - M., 2006.

4. Vishnyakov S. M. Professional'noe obrazovanie. Slovar». Klyuchevye ponyatiya, terminy, aktual'naya leksika.- M., 1999.

5. Vygotskii L. S. Avtorskii terminologicheskii slovar».-M., 2014.

6. Vygotskii L. S. Psikhologiya.-M., 2002.

7. Zaripova D. M. Bor'ba s prestupnost'yu marginal'nykh grupp naseleniya: teoreticheskie i prikladnye problemy.-Kazan», 2000.

8. Mardakhaev L. V. Sotsial'naya pedagogika. Osnovy kursa: uchebnik. - 5-e izd., pererab. i dop.-M., 2011.

9. Mudrik A. V. Sotsial'naya pedagogika. 6-oe izd., pererab i dop.-M., 2007.

10. Pedagogicheskaya entsiklopediya: Vospitanie zdorovogo obraza zhizni uchashchikhsya.-M., 2005.

11. Pobegailo A. E. Semeinoe neblagopoluchie v sisteme determinatsii prestupnogo povedeniya nesovershennoletnikh: dis. ... kand. yurid. nauk. - M., 2006.

12. Rean A. A. Razvitie i sotsializatsiya lichnosti v sem'e. - Rezhim dostupa: http://narcom.ru/parents/ parents $/ 20 . h t m l$

13. Tard G. Sotsial'naya logika. — SPb., 1996. 
14. Filosofskii entsiklopedicheskii slovar»/Gl. red. L. F. Il'ichev, P. N. Fedoseev, S. M. Kovalev, V. G. Panov.- M., 1983.

15. Yuvenal'naya kriminologiya: uchebnik dlya studentov, obuchayushchikhsya po spetsial'nosti «Yurisprudentsiya» / V. A. Lelekov, E. V. Kosheleva. - 2-e izd., pererab. i dop.— M., 2014. 